\section{Resumo}

Este artigo apresenta alguns elementos que podem permitir uma melhor compreensão do Transtorno de Déficit de Atenção e Hiperatividade. Oprimeiro elemento é determinar a função perturbada - a consciência - e a semiologia clássica dessa função; o segundo, apontar para uma ideologia naturalista que sustenta o diagnóstico em termos de transtorno; o terceiro é a maneira pela qual a psicanálise considera a consciência; e o quarto, uma breve consideração sobre como a inibição em Freud e Lacan podem auxiliar no entendimento desse transtorno.

Descritores: psicanálise; inibição; TDAH; sujeito.

\title{
ELEMENTOS PARA ENTENDER O TRANSTORNO DE DÉFICIT DE ATENÇÃO E HIPERATIVIDADE - TDAH
}

\section{Roberto Pires Calazans Matos}

\section{Introdução}

$\mathbb{E}_{\text {Am }}$ "Inibição, sintoma e angústia", Freud (1926/1996) nos diz que a inibição é "a expressão de uma restrição da função do eu" (p. 93). Mas qual função do eu é inibida? A de uma ação no ambiente. Temos aí a restrição da função consciencial do eu. Como o próprio Freud diz mais adiante:

Parece-me que o eu obtém essa influência em virtude de suas vinculações íntimas com o sistema perceptual - vinculações que, como sabemos, constituem sua essência e proporcionam a base de sua diferenciação do isso. A função desse sistema, o qual denominamos de Pcpt-Cs., está ligado à manifestação da consciência. (p. 96).

Ora, ao lidarmos com a sintomatologia de um transtorno como o Transtorno de Déficit de Atenção e Hiperatividade (TDAH), estamos

- Professor adjunto do Programa de Pós-Graduação em Psicologia da Universidade Federal de São João del Rei (UFSJ), São João del Rey, MG, Brasil. 
lidando também com perturbações do sistema percepto (Atenção) e motor (Hiperatividade). Em geral, essa perturbação também se caracteriza por uma desorganização da atuação do indivíduo com seu ambiente, de sua relação com o espaço e com o tempo. Clinicamente, no entanto, é insuficiente localizar a função perturbada para uma explicação e orientação do tratamento.

Nosso objetivo é demonstrar que essa função percepto-motora perturbada é o que classicamente chamamos de processo psicológico da consciência, além de apontar quatro encaminhamentos para tentar entender o TDAH. O primeiro encaminhamento refere-se à semiologia clássica da consciência; o segundo, à ideologia que sustenta a semiologia atual desse transtorno; o terceiro diz respeito à maneira pela qual Freud entende a função da consciência e o modo como a inibição pode se tornar uma referência para explicar o TDAH; e o quarto refere-se à relação que Lacan traça entre inibição e resposta à angústia e sobre como ela também pode auxiliar nessa explicação.

\section{Dificuldades na definição do TDAH}

A psiquiatria biologista atual vê o TDAH a partir do discurso ideológico da naturalização das patologias e da consideração de uma realidade independente do sujeito.

Esse transtorno afeta as duas dimensões da consciência psicológica, tal como Freud a definiu: a dimensão da percepção - atingida pelo chamado déficit de atenção - e a dimensão motora - atingida pela denominada hiperatividade. "Esta patologia é essencialmente caracterizada pela dificuldade de manter atenção, por agitação e inquietude, que muitas vezes podem configurar hiperatividade e impulsividade" (Graeff \& Vaz, 2006, p. 269). A consequência dessa definição é sua insuficiência para estabelecer um diagnóstico diferencial e estrutural. Tal insuficiência se reflete na grande variação de índice de prevalência entre os diversos estudos:

TDAH é, juntamente com o Transtorno Desafiador Opositivo e o Transtorno de Conduta, um dos três transtornos mais comuns no dia a dia profissional de pediatras, psicólogos e psiquiatras. Sua prevalência é estimada em 3\% a $6 \%$ da população infantil geral, mas outros estudos encontraram índices de prevalência com ampla variância (de 3\% a 26\%) no mesmo tipo de população. (Graeff \& Vaz, 2008, p. 342) 
Essa ampla variação, segundo Gretchen e Andrea (2003), não deixa de impactar o nível no qual o diagnóstico se dá. Alguns consideram que ele deve ser considerado um desvio do desenvolvimento que afetaria de $3 \%$ a 5\% da população infantil. Outros o consideram uma doença biológica e, com isso, o índice populacional é bem maior, sendo impossível de ser definido. Os defensores da primeira visão acusam os que defendem a segunda de serem responsáveis pelo aumento da prevalência do diagnóstico de TDAH. Acusação que nos parece correta, uma vez que hoje o tratamento de quem é assim diagnosticado passa, quase que necessariamente, pelo uso de medicação - anfetaminas e metilfenidato -, visto que a síndrome é tomada como uma disfunção neuroquímica. Esses dados demonstram que o transtorno está diretamente associado ao uso de metilfenidato e que houve, na década de 1990 , aumento de $700 \%$ no uso de psicoestimulante em crianças americanas que sugeriria uma overdiagnosis e tratamento inadequado. Eles chegam a dizer que não se trata de uma questão universal nos Estados Unidos, mas de uma imprecisão no diagnóstico que leva ao aumento de casos em alguns lugares e à diminuição em outros.

Tendlarz (2008) aponta para dados em que houve o aumento de 500 mil casos diagnosticados na década de 1987 para 4,4 milhões de casos dez anos depois nos Estados Unidos. É curioso, como demonstra Hanna (2003, p. 147), que a síndrome de déficit de atenção tenha surgido em 1902 por obra de um médico inglês e que, já nessa época, estava associada à hiperatividade e ao aspecto motor da consciência. Ora, as funções que são perturbadas são as mesmas que Freud atribui à inibição. Acreditamos que é pela via inibição que podemos começar a pensar um modo de esclarecer o TDAH, vinculação que não é feita pela psiquiatria atual.

Para começarmos a trazer elementos para entender o TDAH, iremos recorrer, em primeiro lugar, à psicopatologia clássica. $\mathrm{Na}$ psicopatologia clássica, essa descrição ganha outros matizes quando se trata de pensar não somente a respeito de transtornos, mas também a respeito da função que é perturbada por esse transtorno: a consciência. É o que veremos a seguir, ao falarmos dos transtornos da consciência a partir da semiologia.

\section{Transtornos da consciência}

Os transtornos da consciência podem ser divididos, classicamente, em dois grandes grupos: alterações da consciência vígil e da orientação espaço-temporal. No primeiro grupo, encontramos a hipervigilância psíquica e motora, na qual podemos identificar baixo rendimento nas tarefas e dificuldades de integração por aumento na captação dos estímulos vindos do 
ambiente. Também é acompanhado de hiperatividade. E encontramos seu simétrico inverso, a hipovigilância, em que há uma diminuição na capacidade vígil, levando o sujeito a ter desde dificuldades na execução de ordens complexas (confusão) até impossibilidade de responder a estímulos (coma psíquico).

Já os transtornos da ordem da orientação podem se subdividir em alopsíquico e autopsíquico. A orientação seria a capacidade de apreciar dados sobre nossa situação real no ambiente em relação ao tempo e ao espaço. Em relação ao tempo, é importante salientar que é o "tempo cronológico, que é o tempo físico" (Álvarez, Sauvagnat \& Estéban, 2004, p. 468). Iremos nos deter somente no alopsíquico, uma vez que é nesse aspecto que temos referências mais explícitas sobre as questões conscienciais vinculadas à ação no ambiente. Podemos ter a desorientação apática, que ocorre em situações normais, como férias. Patologicamente, pode levar a uma ignorância absoluta do tempo, mas, se estimulado adequadamente, pode voltar a se orientar, como em algumas formas autísticas da esquizofrenia e da melancolia. Além disso, podemos nos reportar à desorientação temporal propriamente dita. Como dizem Álvarez, Sauvagnat e Estéban (2004):

A orientação no tempo permite ao sujeito conhecer o dia, hora, ano, etc. em que vive e a ordem de sucessão dos fatos. Quando está alterada, os erros costumam seguir esta ordem: primeiro erra o dia do mês (muitas vezes ocorre no indivíduo normal), em seguida o ano, depois o dia da semana e, por último, o mês ou a época do ano. Em um grau mais avançado da desorientação, o doente não sabe nem se é manhã ou tarde, se é dia ou noite. (p. 468, tradução nossa).

No que diz respeito aos fenômenos psicopatológicos relativos à atenção, encontramos transtornos no ordenamento espacializado do tempo. Se tomarmos a função da atenção, que Freud situa como uma das funções da consciência, encontraremos problemas relativos à diminuição da atenção (hipoprosexia) e à perda duradoura de concentração, que ocorrem geralmente na diminuição da capacidade vígil e em autismo; encontraremos também uma falsa diminuição da atenção, que é quando o sujeito está concentrado somente em alguns pensamentos ou estímulos, estando presente em casos de deprimidos, obsessivos e ansiosos, entre outros; e encontraremos, ainda, aumento da intensidade da atenção (hiperprosexia), que leva o sujeito à fuga de ideias maníacas e a saltos na concatenação dos pensamentos, ocorrendo em casos de obsessivos, hipocondríacos ou esquizofrênicos.

Esse abalo na capacidade vígil, seja por aumento ou diminuição da intensidade da atenção, altera a percepção do tempo cronológico. A ideia de saltos, de perda de concentração, implica necessariamente a falta de ordenamento temporal no encadeamento dos eventos tais como 
seriam notados no ambiente a partir do momento em que afetam a consciência. E, se tomarmos a definição de Transtorno de Déficit de Atenção e Hiperatividade do Manual Diagnóstico e Estatístico de Transtornos Mentais, encontraremos muitos desses sinais e sintomas vinculados à semiologia da consciência:

Desatenção: (a) frequentemente não presta atenção a detalhes ou comete erros por omissão em atividades escolares, de trabalho ou outras/ (b) com frequência tem dificuldade para manter atenção em tarefas ou atividades lúdicas / (c) com frequência parece não ouvir quando lhe dirigem a palavra.... (e) com frequência tem dificuldade de organizar tarefas e atividades.... (h) é frequentemente distraído por estímulos alheios às tarefas. Hiperatividade: (a) frequentemente agita as mãos ou os pés ou se remexe na cadeira /(c) frequentemente corre ou escala em demasia, em situações impróprias.... (f) frequentemente fala em demasia.... (h) com frequência tem dificuldade para aguardar a sua vez. (APA, 2002, p. 118)

No entanto, esses aspectos semiológicos também são insuficientes para a realização de um diagnóstico propriamente diferencial, em que se possa determinar a estrutura clínica de um sujeito, uma vez que muitas dessas perturbações podem ocorrer em estruturas clínicas distintas. Se nos detivermos somente nos fenômenos conscienciais, apenas nos colocaremos diante de fenômenos sem explicá-los, submetendo-nos a uma ideologia cujos princípios exporemos seguir, bem como a crítica da psicanálise a ela.

\section{Ideologia naturalista}

Não podemos deixar de notar a existência de um discurso ideológico que sustenta o modo de pensar os fenômenos, sem a preocupação com as condições estruturais de seu aparecimento. É uma ideologia naturalista, que pressupõe uma realidade prévia ao trabalho de um sujeito e independente de um discurso. Como consequência dessa ideologia, a partir da década de 1960, a direção do tratamento passa a ser pautada pelo uso de medicamentos e de condicionamento do agir do indivíduo a certa noção de ordem pública.

Dito de outro modo: trata-se de uma ideologia que se ampara em uma conaturalidade entre o sujeito e objeto. Visa a oferecer um tratamento imaginário, colocando em jogo noções tais como a de 
proporção e harmonia entre o objeto que é percebido e o sujeito que percebe. No entanto, para Freud, entre as percepções e as ações do sujeito no ambiente, há todo um sistema de representações que impede que tenhamos uma relação de harmonia. A esse sistema de representações Freud chamou inconsciente e Lacan, discurso do Outro.

Essa ideologia já fora criticada por Lacan (1998) em "De uma questão preliminar a todo tratamento possível da psicose", em que ele aponta o equívoco de situar o sujeito como inteiramente identificado ao sujeito da percepção. Não se trata, no psicótico, de um erro perceptual, e sua alucinação não é da ordem de uma percepção sem objeto, e sim de um discurso fragmentado. Assim como na neurose encontramos o sujeito determinado por um lugar discursivo, tornando possível compartilhar experiências - menos no nível do sintoma, que aponta para a singularidade do sujeito -, na psicose temos outro trabalho em estabelecer um laço com o Outro que vai desde a construção de um delírio até o que Jacques-Alain Miller (2007) chamou de invenções psicóticas.

Lacan (2003, p. 475) demonstra, em um texto, como o corpo não pode ser reduzido a uma biologia e como ele depende de um discurso. Suas funções são provenientes do discurso. Não se trata de um déficit perceptivo ou motor. $\mathrm{O}$ autor diz que a função de cada um dos órgãos faz questão para o ser falante. É no que se especifica o esquizofrênico, por estar tomado sem o auxílio de nenhum discurso estabelecido. Miller comprova isso com um exemplo: o caso de um sujeito que tinha o sentimento de estar fora do corpo. Para ligar-se ao corpo, ele tinha de colocar faixas sobre a cabeça, para que ela não se desprendesse, assim como usar anéis nos dedos e ataduras sobre os seus órgãos. A ausência de discurso faz com que o corpo próprio se torne enigmático para o sujeito.

O problema do uso dos órgãos é especialmente agudo para os esquizofrênicos e ele tem de contar com recursos sem auxílio dos discursos estabelecidos; quer dizer, está obrigado a inventar um discurso, está obrigado a inventar seus apoios, seus recursos, para poder fazer uso de seu corpo e de seus órgãos. (Miller, 2007, s.p.).

Se em relação ao corpo temos a necessidade de um discurso para que ele possa adquirir certa unidade, em relação às funções desse mesmo corpo - aí incluídas a percepção, a atenção e a motilidade - 
não seria diferente. Para demonstrar isso, não precisamos apelar para uma saída tão radical como na esquizofrenia; basta nos remetermos à questão das teorias sexuais infantis: diante da diferença dos sexos, o menino, de acordo com Freud, se verá confrontado com uma questão e formulará respostas: por que uns têm e outros não têm o pênis? Diante dessa questão, sua elaboração vai desde o desmentido da percepção de que as meninas não têm o pênis - ele ainda é pequeno e crescerá, ou ele estava ali e foi arrancado - até a conclusão de que o seu pode ser arrancado. A esse complexo Freud denominará castração. Ele só é possível porque nós temos aqui a afetação do organismo pelo significante, fazendo com que, no caso do ser falante, as coisas se deem de modo diferente. Como diz Jean-Louis Gault: "O organismo do único animal que fala é, em seu conjunto, e sempre, mergulhado no campo da linguagem, submetido à função da palavra e assujeitado à função da escrita" (Gault, 2008, p. 3).

Desse modo, as funções corporais são sempre problemáticas, necessitando de um discurso para ordená-las. E, em relação ao caso da teoria sexual infantil, o sujeito, caso não tenha a resposta radical da esquizofrenia, irá localizar apenas o falo como um órgão fora do corpo. É aí que encontramos o registro da sexualidade transtornada pelo significante: o pênis deixa de ter apenas a função de micção ou reprodução. É a ereção ou sua falta que, fenomenicamente, demonstra essa afetação do corpo pelo significante de um discurso: o pênis não sobe ou sobe em momento apropriado não somente em razão de uma mera fricção, mas também mediado por um desejo que transtorna a função. Esse transtorno será ampliado para outras partes do corpo, como bem demonstram as contraturas histéricas que levam um determinado sujeito a não conseguir tocar violino, etc.

Essas explicações sobre a importância de não colocar o sofrimento psíquico somente no nível fenomênico leva-nos a situar teoricamente a tópica do consciente.

\section{Teoria freudiana do consciente diante da hipótese do Inconsciente}

Freud (1915/1996) irá afirmar quatro características próprias ao inconsciente: a não contradição, o processo primário, a substituição 
da realidade externa pela realidade interna e o desconhecimento do tempo. Podemos afirmar, em contraposição, que o tempo espacializado e a realidade externa são características próprias ao sistema consciente. Mas precisamos agora definir com mais precisão o que Freud chama de consciente.

Em primeiro lugar, é preciso notar que o termo "consciente" não é unívoco no texto de Freud. Se falamos que Freud subverte a noção de aparelho psíquico ao não fazer com que o todo desse aparelho seja subsumido à consciência, ele faz, na verdade, uma dupla subversão: tanto da noção filosófica quanto da noção psicológica de consciência. Em alemão, Freud usa o termo Gewissen para se referir à consciência moral da filosofia e Bewustssein para se referir à consciência psicológica. O primeiro está relacionado à consciência como condição de possibilidade a priori para toda e qualquer experiência possível; o segundo diz respeito à função de perceber e reconhecer algo, seja no ambiente, seja no interior do sujeito.

Freud subverte ambos os termos ao apontar para a dimensão do inconsciente: nesse aspecto, o sujeito já não é mais origem a priori de qualquer experiência possível. Freud vai apontar que, para surgir o eu, será necessária uma nova ação psíquica daquele que cuida do bebê, demonstrando que o sujeito não é originário, mas um efeito dessa ação.

Contudo, quando lidamos com a questão da definição do tempo 
por Freud no registro do consciente, estamos às voltas com a dimensão psicológica. Se essa função psicológica está no nível do reconhecimento de um objeto no ambiente, ela é compatível com a definição de Freud quando afirma que a consciência é um sistema de percepção e de ação no ambiente. A consciência, nesse caso, não é tão somente um sistema de memória, não retém traços mnêmicos (tarefa do inconsciente e do pré-consciente). É um sistema de localização e de ação no ambiente. A consciência é um sistema de entradas e saídas, mas comandada e filtrada pelas representações inconscientes.

Levando em consideração essa definição psicológica, como podemos então pensar o tempo nesse sistema de localização no ambiente de um objeto no qual uma ação poderá ser efetivada? Em primeiro lugar, é necessário ficar claro que tempo pressupõe algum modo de organização e limite: organização dentro de certa lógica que impõe os limites para determinada experiência. E quais seriam esses limites senão o da ordenação consciente, que pressupõe o espaço por pensar em uma ação no ambiente. Se a consciência está necessariamente ligada ao espaço, e Freud situa o tempo no registro do consciente, a sua definição passa necessariamente pela ordem da espacialização. É o tempo que se ordena na sucessão de fenômenos, contabilizado pelo cronômetro. É a esse tempo que geralmente nos referimos quando dizemos que alguém está atrasado ou que alguém perde tempo. É nessa dimensão consciencial em que a percepção e o agir estão em primeiro plano que podemos situar os fenômenos do Transtorno de Déficit de Atenção e Hiperatividade.

No entanto, se pretendemos dar um encaminhamento para explicar o TDAH, é importante agora apontar uma direção mais clínica. E o faremos a partir da relação entre inibição e TDAH, para, em seguida, ver como a inibição, conforme entendida pela psicanálise, pode servir de alavanca explicativa para o TDAH.

\section{Inibição: um conceito para começar a entender o TDAH}

A relação entre inibição e TDAH já foi apontada pela psicanalista Silvia Bleichmar (2001): 
os famosos transtornos de desatenção com hiperatividade (o famoso ADD), que são falhas na organização da tópica e na estrutura de ligação, que permite a constituição da atenção e que, em última instância, é a forma pela qual o ego se permite inibir e escolher, dentro do conjunto de estímulos que recebe, acarretando evoluções posteriores muito mais graves que as previstas. (Ferreira \& Molloy, 2001, p. 198).

Cremos que uma primeira direção para pensar essa articulação é pensar o porquê do aumento de diagnósticos de TDAH: se ele é uma perturbação da função do eu ligada à consciência, uma vez que coloca em questão o aspecto motor - inibido por um lado, agitado, por outro -, é por valorizar a dimensão da atividade da criança no ambiente. Não é gratuito que o diagnóstico de TDAH é geralmente feito quando as crianças atingem a idade escolar. Desse modo, temos um pendor para o viés educativo que não deixa de estar acompanhado do viés ideológico sobre como a criança deve ser. Uma mudança no discurso do mestre acaba por viabilizar uma mudança no aparecimento das respostas do sujeito. Numa época em que o mestre se assentava em lugar de poder, sua figura não podia sugerir senão a inibição; numa época em que o próprio discurso tem dificuldades de se manter, não temos mais a inibição como correlato, e sim a agitação motora. É a ideologia naturalista vigente que sustenta o aumento do índice de casos de TDAH. Vejamos, então, como considerar a inibição.
A inibição se torna preponderante na clínica psicanalítica infantil somente após 1920, e estava atrelada à questão da eficácia do tratamento psicanalítico de crianças (Santiago, 2005). A questão colocada era se se tratava de psicanálise propriamente dita ou de um método educativo fundamentado na psicanálise com fins profiláticos: evitar que a criança desenvolvesse uma neurose que impediria um desenvolvimento adequado. Ora, apelar ao bom desenvolvimento sem questionar sobre suas vicissitudes é o mesmo que apelar à ideologia naturalista que também viceja nas definições do TDAH. É pautar-se por um realismo que levaria o sujeito não necessariamente a um bom desenvolvimento, mas a uma mera adaptação a um padrão preordenado.

A consequência do realismo da definição é considerar a inibição um desvio de desenvolvimento padronizado. Essa inibição perturbaria as funções que deveriam ser desenvolvidas para agir competentemente no ambiente. Trata-se, em verdade, mais de uma perspectiva evolutivo-biológica que pensa o sujeito em termos de desenvolvimento adaptativo e que exige a interação da criança com o mundo, "e então o olhar do observador é centrado, preferencialmente em tudo que é da ordem da ação, das trocas e da adaptação desse ser ao meio ambiente" (Santiago, 2005, p. 75).

Ora, continuando neste contraponto entre TDAH e inibição como perturbação de dois polos do cons- 
ciente - a inibição, junto com a hiperatividade afetando o aspecto motor e com o déficit de atenção afetando o aspecto perceptual -, podemos depreender que o diagnóstico aqui também é insuficiente se nos mantivermos no nível fenomênico. Por exemplo: mesmo para profissionais que se valem dessa categorização, o diagnóstico é problemático e "a primeira dificuldade é a inexistência de testes físicos, neurológicos ou psicológicos que possam realmente provar a presença do TDAH numa criança ou num adolescente" (Graeff \& Vaz, 2008, p.342). Essa ausência é, curiosamente, o ponto de partida de Freud.

Freud preferiu seguir o caminho da clínica para tratar da inibição. Ele diz que na inibição o uso da função motora está perturbado por implicar a realização da significação sexual, que pode suscitar, ora um conflito do eu com o isso - inibições específicas -, ora com o supereu - inibições no trabalho. Para Freud, a limitação das funções do eu na inibição não poderiam ser situadas apenas como um déficit; ao buscar um princípio explicativo, traz para primeiro plano a função da sexualização das funções. Ora, uma função só pode ser sexualizada, no sentido em que Freud dá à sexualidade - perverso-polimorfa, ou seja, sem um padrão biológico que a regule -, com a intervenção do fator inconsciente. Ou, para dizer em termos lacanianos: a sexualidade só pode ser perverso-polimorfa no campo da fala e da linguagem.
Se, por um lado, Freud se reporta às funções do eu que seriam prejudicadas, por outro, ele considera que apenas esse aspecto seria insuficiente para uma explicação clínica da inibição. Desse modo, Freud coloca a inibição como uma resposta que podemos chamar de ordem estrutural. Freud inicia seu trabalho sobre a clínica infantil e a inibição com o pequeno Hans, cujos sintomas são acompanhados de uma inibição em sair de casa por medo de cavalo. Freud não trata diretamente do sintoma ou da inibição, mas irá buscar o que tornou possível o aparecimento dos dois: o complexo de Édipo e o complexo de Castração e a angústia que surge em relação a eles. É a essas questões que Hans responde com o cavalo como sintoma e a inibição como perturbação motora.

A diferença, então, apontada por Freud entre inibição e sintoma é proveniente da modalidade de defesa que será empregada para evitar a angústia: no que tange ao sintoma, ocorre uma resposta mediante o recalque, em que temos a substituição da representação que fere o princípio do prazer por outra que possa advir com aumento da carga afetiva; na inibição, a resposta não passa pelo recalque, e sim apenas por uma medida de precaução para que o conflito não advenha. No caso do sintoma, temos uma formação do inconsciente; no caso da inibição, a função de evitar a angústia é "homóloga ao sintoma, mas não é homogênea ao sintoma quanto ao 
seu mecanismo" (Hanna, 2003, p. 150). Ao que acrescentaríamos: é uma resposta que não apela ao jogo dos significantes, atendo-se basicamente ao nível do consciente. Desse modo, temos as funções do eu hiperinvestidas, mas sem o trabalho de deslocamento e condensação do inconsciente. O resultado, ora aparecerá sob a forma de inibição - impedimento da ação -, ora aparecerá por uma distração - impedimento da atenção -, ora aparecerá por uma hiperatividade em que o sentido da ação se perde.

Freud então reporta a inibição a uma perturbação da função do eu em sua dimensão consciente. Essa perturbação é dividida em quatro modos: inibição sexual, que pode ser alcançada por vários meios e se manifestar de diversos modos; inibição da função da nutrição; inibição da locomoção em alguns quadros neuróticos; e inibição no trabalho. O que há de comum entre essas modalidades de inibição é que atuam sobre a função do agir e que, do mesmo modo da semiologia psiquiátrica, podem ocorrer em diversas estruturas, o que não nos permite sair dos níveis dos fenômenos para o nível em que eles são explicados. É um trabalho necessário, porém não suficiente.

Mas o que significa essa resposta se dar no nível consciente? " $\mathrm{O}$ inibido evita a angústia pela via do imaginário, isto é, pelo registro do eu, impondo-lhe um limite em alguma de suas funções. O registro do imaginário é aquele que encobre toda e qualquer falta" (Hanna, 2003, p. 154).

Outro ponto importante a ser destacado do texto de Hanna: ela aponta a importância do objeto cuja presença perturba as funções de percepção e motilidade do eu. Elemento que não pode ser considerado nem imaginário - pois o imaginário se caracteriza por tentar fechar os furos - nem simbólico - pois o simbólico desarticulado dos outros registros pode levar a uma interpretação infinita.

Se nos lembrarmos de Lacan no seminário sobre a angústia, ele dirá que a angústia não é sem objeto e que, além das respostas à angústia que se elaboram sob a forma de sintoma, podemos encontrar outras respostas que não passam pelas formações do sintoma, como o acting-out, a passagem ao ato e a inibição. Santiago (2005, p. 136), situa a inibição e os atos como opostos. Outros a situam em sequência às patologias do ato, por se colocar como problema para o sujeito justamente na dimensão do agir:

podemos começar assinalando que, em sentido estrito, tudo que Lacan desenvolve nesse Seminário sobre a inibição é, na realidade, a elaboração da 
patologia do sujeito colocado do lado do objeto como desejante. Essa patologia se elaborará através dos conceitos de inibição, acting-out e passagem ao ato. (Rabinovich, 2005, p.36)

Ora, Freud mesmo diz que a inibição é uma resposta do sujeito que visa a evitar o recalcamento. Mas em que nível essa resposta se dá? No nível consciente. Ao ocorrer nesse nível, podemos dizer, lacanianamente, que é um modo imaginário de responder à intromissão do objeto. É o que encontramos na inibição e no TDAH. Então vejamos o que Lacan diz sobre a inibição em relação à angústia.

\section{Sintoma posto no museu?}

Como podemos pensar a ideia de Lacan de que a inibição - e acrescentaríamos: o seu simétrico inverso do TDAH também - é um sintoma posto no museu? É posto no museu porque não é nem um sintoma como formação do inconsciente - que demandaria uma interpretação e uma temporalidade propriamente simbólica que é abordada por Lacan no tempo lógico como tempo de compreender - , nem um ato que demanda uma temporalidade que implica o presente da demanda - no caso do acting-out-, nem um estilhaçamento da temporalidade - como no caso da passagem ao ato. É posto no museu por ser uma resposta imaginária - e aí reside a dificuldade de muitos analistas em fazer com que o sujeito saia da posição que o tratamento dado ao objeto como resto implica para o sujeito: uma definição de ser como um deficiente:

O "sintoma posto no museu" acarreta mal-estar, baixa autoestima, desânimo - queixas frequentes destes sujeitos -, expressando-se também em alguns estados depressivos que nos dão notícia de um gozo autoerótico. No órgão fica retido o objeto a, enquanto suplência do ser. Surgem assim nomes que designam o ser do sujeito, como objeto a para o outro, de maneira pejorativa: "sou burro", "sou idiota", "sou um ET", "sou um merda", "sou um nada". Esse ser - objeto a - surge coberto pelos significantes burro, merda, incapaz, entre outros. (Hanna, 2003, p. 153)

Desse modo, podemos concordar parcialmente com Rabinovich quando inclui a inibição entre as patologias do ato. Ela o faz por situar aí um curto-circuito sujeito-objeto. Mas esse curto-circuito nem sem- 
pre situa a resposta do sujeito como um ato. No caso de inibição-TDAH, é mais uma patologia da atividade para evitar um ato. Não podemos confundir os atos com ações. Um ato, para ser efetivo, deve situar um corte com uma estruturação simbólica propriamente dita; nos casos de inibição e de TDAH, temos, ora um impedimento da atividade, ora um sobreinvestimento na atividade. Afinal, se a inibição é um sintoma posto no museu, ele não rompeu com a estrutura simbólica que o determina.

Nessa dimensão de problemas, Santiago (2005) chega a afirmar que a inibição pode servir como uma terapêutica possível para os atos do sujeito, o que leva a corroborar nossa afirmação de que a inibição não pode ser situada na dimensão dos atos.

No que tange à dimensão temporal do par inibição-TDAH, também encontramos elementos que não nos permite dizer que se trata de uma patologia do ato. Nesse sentido, uma passagem de Brodski é importante: "o ato tem uma ligação estreita e estrutural com a questão da temporalidade, pois não se passa a vida fazendo um ato.... Um ato é instante, é o momento em que se salta. Sua temporalidade é a de um instante" (Brodski, 2004, p. 18). A inibição e a hiperatividade, por serem respostas imaginárias ao objeto da angústia, acabam por manter a resposta do sujeito em relação a acelerações e retardos, mas sempre referidos ao cronômetro. Uma patologia subjetiva, que leve em conta a temporalidade propriamente dita, dependerá de outra maneira de trabalhar o objeto da angústia: ou pela via da cifração sintomática - ou seja, um tratamento pelo simbólico -, ou pela via dos atos.

\section{Conclusão}

Acreditamos que uma análise mais pormenorizada do trabalho de constituição do eu, no qual entraria a questão do narcisismo, pode ser um indicador importante para a questão, por conjugar o aspecto estrutural e desenvolvimental. No entanto, isso ultrapassaria o escopo deste artigo, que visa tão somente a apresentar alguns elementos para o entendimento do TDAH. Desse modo, podemos extrair algumas conclusões desses elementos que trouxemos em nossa discussão: a primeira é que não podemos pensar a noção de transtorno sem pensar que função é essa que é transtornada. Isso é importante porque nos permite situar melhor um sintoma, fazendo que ele não apenas entre como um dado de realidade, mas que desempenhe um papel numa dinâmica subjetiva. A segunda é que ater-se apenas aos dados fenomênicos é fruto de uma ideologia naturalista, resultado de um discurso específico, e não somente um fenômeno que se impõe por si. $\mathrm{O}$ ponto importante, nesse caso, é que podemos ver que muitos diagnósticos ou aumento da prevalência de casos não são desacompanhados de um 
discurso. Uma terceira conclusão é sobre como podemos encontrar um outro caminho a partir da análise da psicopatologia clássica articulada ao conceito de inibição em psicanálise. Acreditamos que a inibição demonstra como um conceito pode servir para esclarecimentos do que é um transtorno, mesmo que sua presença fenomenológica seja contrária à sintomatologia clássica da inibição, e como ela pode, a partir daí, ser um balizador para o trabalho clínico com sujeitos que hoje são diagnosticados como portadores do Transtorno de Déficit de Atenção e Hiperatividade.

\section{ELEMENTS TO UNDERSTAND ATTENTION DEFICIT HYPERACTIVTTY DISORDER $-A D H D$}

\section{Abstract}

This article presents some elements that can allow us to better understand the Attention Deficit Hyperactivity Disorder. The first element is to determine which function is disturbed - consciousness - and its classic semiology; the second element is to point out a naturalist ideology that supports the diagnosis in terms of disorder; the third is the manner how psychoanalysis sees consciousness; and the fourth presents a brief consideration of how the inbibition in Freud and Lacan can help us to understand this disorder.

Index terms: psychoanalysis; inbibition; ADHD; subject.

ELEMENTOS PARA ENTENDER EL TRASTORNO POR DÉFICIT DE ATENCIÓN CON HIPERACTIVIDAD - TDAH

\section{RESUMEN}

Este articulo presenta algunos elementos que nos permiten comprender mejor el Trastorno por Déficit de Atención con Hiperactividad. El primer elemento consiste en determinar La alteración de la función - la conciencia - y la semiología clásica de esta función; el segundo apuntar a una ideología naturalista que apoya el diagnóstico en términos de trastorno; la tercera es la manera en que psicoanálisis considera la consciência; y el cuarto tras uma breve consideración como la inbibición de Freudy de Lacan puede ayudar en la comprensión de este trastorno.

Palabras clave: psicoanálisis; inbibición; TDAH; sujeto.

\section{REFERÊNCIAS}

Álvarez, J. M., Sauvagnat, F., \& Estéban, R. (2004). Fundamentos de psicopatologia psicoanalitica. Madrid: Síntesis.

Associação Psiquiátrica Americana. (2002). Manual diagnóstico e estatístico de transtornos mentais. 4. ed. - Revista (DSM-IV-TR). Porto Alegre: Artmed.

Brodski, G. (2004). Short story (V. Ribeiro, trad.). Rio de Janeiro: Contracapa.

Freud, S. (1996). O inconsciente. In S. Freud, Edição standard brasileira das obras psicológicas completas de Sigmund Freud ((J. Salomão, trad., Vol. 14, pp. 171-222). Rio de Janeiro: Imago. (Trabalho original publicado em 1915)

Freud, S. (1996). Inibição, Sintoma e Angústia. In S. Freud, Edição standard brasileira das obras psicológicas completas de Sigmund Freud (J. Salomão, trad., Vol. 20, pp. 81-171). Rio de Janeiro: Imago. (Trabalho original publicado em 1926)

356 Estilos clin., São Paulo, v. 18, n. 2, mai./ago. 2013, 342-357. 
Ferreira, J. C., \& Molloy, C. (2001). Entrevista com Silvia Bleichmar. Psychê 5 (8), 193-203.

Gault, J.-L. (2008). Tratamento psicanalítico de um caso de hiperatividade de uma jovem adolescente. Almanaque on line: Revista do do Instituto de Psicanálise e Saúde Mental de Minas Gerais. Recuperado em 18 de março de 2010, de http://www.institutopsicanalise-mg.com.br/psicanalise/almanaque/ almanaque3.htm

Graeff, R. L., \& Vaz, C. E. (2006) Personalidade de crianças com Transtorno de Déficit de Atenção e Hiperatividade (TDAH) por meio do Rorschach. Psicologia: Teoria e Pesquisa, 22 (3), 269-276.

Graeff, R. L., \& Vaz, C. E. (2008). Avaliação e diagnóstico do transtorno de déficit de atenção e hiperatividade (TDAH). Psicologia USP, 19 (3), 341-361.

Gretchen, B., \& Andrea, P. (2003). ADHD among american schoolchildren: evidence of overdiagnosis and overuse of medication. The Scientific Review of Mental Health Practice, 2 (1). Recuperado em 28 de março de 2010, de http:/ / translate.google. com.br/translate?hl=ptBR\&sl=en\&tl=p$\mathrm{t} \& \mathrm{u}=\mathrm{http} \% 3 \mathrm{~A} \% 2 \mathrm{~F} \% 2 \mathrm{Fwww}$.srmhp. org $\% 2 \mathrm{~F} 0201 \% 2 \mathrm{Fadhd} \cdot \mathrm{html} \&$ anno $=2$

Hanna, M. S. G. F. (2003). O distúrbio de déficit de atenção é "um sintoma posto no museu"? Uma leitura psicanalítica da síndrome do distúrbio de hiper-atividade e déficit de atenção. Latusa, 8, 147-156.

Lacan, J. (1998). De uma questão preliminar a todo tratamento possível da psicanálise. In J. Lacan, Escritos (V. Ribeiro, trad., pp. 537590). Rio de Janeiro: Jorge Zahar.

Lacan, J. (2003). O aturdito. In J. Lacan, Outros escritos (V. Ribeiro, trad., pp. 448-497). Rio de Janeiro: Jorge Zahar.

Miller. J.-A. (2007). La invención psicótica. Virtualia, 16. Recuperado em 01 de abril de 2010, de http://virtualia.eol.org.ar/016/ default.asp?formas/miller.html

Rabinovich, D. (2005). A angústia e o desejo do Outro (A. Lopes, trad.) Rio de Janeiro: Companhia de Freud.

Santiago, A. L. (2005). A inibição intelectual na psicanálise. Rio de Janeiro: Jorge, Zahar.

Tendlarz, S. E. (2008). A atenção que falta e a atividade que sobra: reflexões sobre ADD -ADHH. Almanaque on line: Revista do Instituto de Psicanálise e Saúde Mental de Minas Gerais. Recuperado em 31 de março de 2010, de http://www.institutopsicanalise-mg.com. $\mathrm{br} / \mathrm{psicanalise/almanaque/textos/nume-}$ ro3/A $\% 20$ atenção $\% 20$ que $\% 20$ falta $\% 20$ e $\% 20 \mathrm{a} \% 20$ atividade $\% 20$ que $\% 20$ sobra.pdf

calazans@ufsj.edu.br roberto.calazans@gmail.com

Praça Dom Helvécio, 74 36301-160 - São João Del Rei - MG - Brasil. 